\title{
Bei Anorexia nervosa nimmt auch das Gehirn ab
}

Der Gewichtsverlust bei Anorexia nervosa beeinflusst alle physiologischen Systeme des Körpers, einschließlich das Gehirn. Jetzt wurde untersucht, ob eine erfolgreiche Therapie der Essstörung auch den Volumenverlust im Gehirn rückgängig macht.

-Wissenschaftler der Yale University in New Haven verglichen mit der Magnetresonanztomografie (MRT) die Gehirnvolumendefizite in der weißen und grauen Hirnsubstanz. Die Messungen wurden an 32 Frauen mit Anorexia nervosa und $21 \mathrm{im}$ Alter und BMI passenden, gesunden Kontrollfrauen durchgeführt.

Bei Frauen mit Anorexia nervosa im Hungerstatus war das Volumen der grauen Substanz $(647,63 \pm 62,07 \mathrm{ml})$ im Vergleich mit dem der gesunden Frauen $(679,93 \pm 53,31 \mathrm{ml})$ erniedrigt. Untergewichtige Frauen mit dem längsten Krankheitsverlauf hatten die größten Gehirnvolumenreduktionen. Nach der Behandlung in einer Spezialabteilung normalisierte sich das Gehirnvolumen fast wieder $(662,64 \pm 69,71 \mathrm{ml})$.

\section{Kommentar}

Nach dieser Studie ist sicher, dass untergewichtige erwachsene Frauen mit Anorexia nervosa stark verminderte Volumina der grauen und weißen Hirnsubstanz haben. Durch therapeutische Gewichtszunahme können diese Volumina wieder erhöht werden. Die klinischen Wirkungen dieser Volumenänderungen sind aber noch nicht bekannt.

K. MALBERG .

\section{- C. A. Roberto et al.}

(Department of Psychology, Yale University, Box 208205, New Haven, Connecticut 06520, USA; e-mail: christina.roberto@yale. edu) Brain tissue volume changes following weight gain in adults with anorexia nervosa. Int J Eating Disorders 2010;43: DOI: 10.1002/ eat.20840

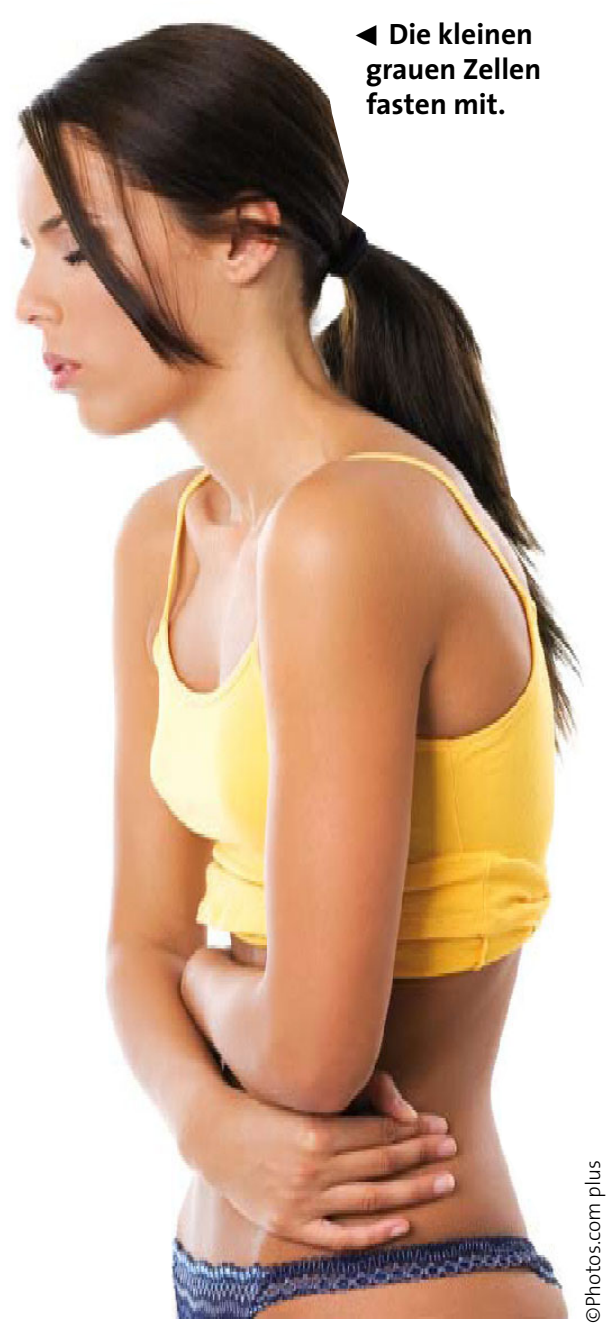

\section{Nanopartikel-PSA-Test erkennt Prostatakarzinomrezidive}

Der konventionelle Test auf prostataspezifisches Antigen (PSA) zeigt bei bis zu $40 \%$ der Prostatektomiepatienten Prostatakarzinomrezidive nicht an. Der Test ist für die geringfügigen PSA-Schwankungen, die hier eine Rolle spielen, nicht sensitiv genug.

- Wissenschaftler der Northwestern University und des University International Institute for Nanotechnology Chicago (USA) entwickelten auf der Basis der Nanotechnologie einen $\mathrm{Na}-$ nosphere-PSA-Test (nPSA-Test), der 300-mal empfindlicher ist als der kon- ventionelle PSA-Test. Damit untersuchten sie retrospektiv eingefrorene Seren von 188 Männern, die vor zehn Jahren eine radikale Prostatektomie durchgemacht hatten. Mit dem konventionellen Test war in diesen Seren kein PSA nachweisbar.

Mit dem nPSA-Test wurden konstant niedrige PSA-Spiegel $(5,8 \mathrm{pg} / \mathrm{ml})$ über mindestens zehn Jahre nachgewiesen, was als Hinweis auf eine Heilung des Prostatakarzinoms gewertet wurde. Das nachgewiesene PSA stammt wahrscheinlich von den periurethralen Drüsen. In einigen Seren fanden sich aber höhere $(10,1 \mathrm{ng} / \mathrm{ml} ; \mathrm{p}=0,016)$ und ansteigende PSA-Werte. Diese Patienten hatten ein Prostatakarzinomrezidiv.

\section{Kommentar}

Mit dem gegenüber dem kommerziellen PSA-Test wesentlich sensitiveren nPSATest ist es möglich, das Prostatakarzinom früher zu diagnostizieren und den Therapieerfolg zu kontrollieren und eventuelle Rezidive zu erkennen.

K. MALBERG =

- http://www.feinberg.northwestern.edu/news/ 2010G-June/Nanoparticle_PSA_Test.html 